\title{
In memoriam Werner Wey (1927-2018)
}

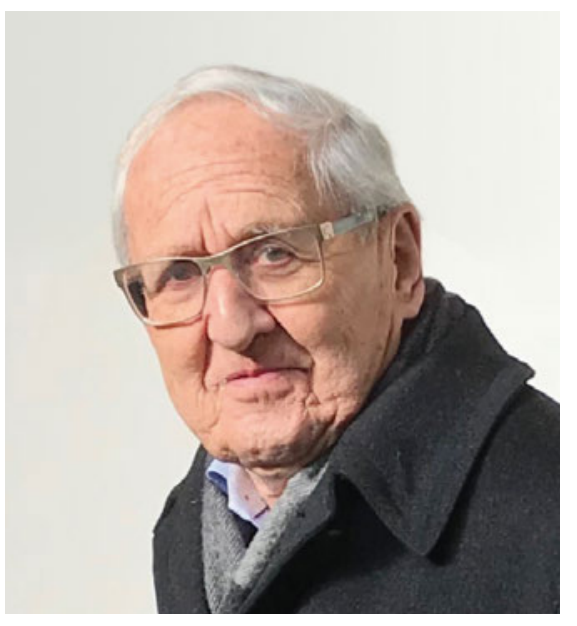

Werner Wey

Professor Dr. Werner Wey war eine herausragende ärztliche Persönlichkeit. Er prägte wesentlich das Fach OtoRhino-Laryngologie sowie das medizinische Leben in Basel und der ganzen Schweiz.

\section{Vom Studium bis zur Professur}

Werner Wey entstammt einer luzerner Artzfamilie. Bereits sein Grossvater und auch sein Vater waren Hausärzte. Das Medizinstudium absolvierte er an den Universitäten Basel, Lausanne und Zürich. Es folgt die Doktorpromotion 1953 bei Prof. Wilhelm Löffler an der Universität Zürich. Seine Asisstentenausbildung absolvierte er am pathologisch-bakteriologischen Institut und an der chirurgischen Klinik des Kantonsspitals Luzern. 1957 begann er seine spezialärztliche Ausbildung an der ORL-Universitätsklinik Basel bei Prof. Erhard Lüscher. Vier Jahre später wurde er Assistent an der Columbia Medical Center, New York, bei Prof. J.J. Conley und R.M. Rankow. 1967 erfolgte die Venia docendi an der Universität Basel, 1972 wurde er zum Professor an der Universität Basel ernannt. Zwei Jahre später verzichtete er auf ein Ordinariat der Universität Innsbruck. Seit 1968 war Werner Wey zudem Stellvertreter von Prof.Dr.C.R.Pfaltz an der ORL-Klinik am Universitätsspital Basel. Ausgehend von der Tradition der geschichtlich ältesten ORL-Klinik (1876) war Werner Wey die treibende Kraft für den Spitalneubau dem heutigen Klinikum 2

Die fachlich hervorragendste Leistung von Werner Wey war die Durchführung der ersten totalen Laryngektomie in Basel. Als führender Hals-Tumorchirurg seiner Zeit erkannte er zudem die Notwendigkeit, die Patienten - nachdem sie durch die Operation ihrer
Stimme beraubt waren - wieder in das soziale Leben zurück zu führen. So gründete er die Schweizerische Gesellschaft der Kehlkopflosen, deren Sitzungen er bis zuletzt besuchte, um den Betroffenen Mut zuzusprechen und ihnen mit Rat zur Seite zu stehen. Im Zusammenhang mit der sprachlichen Rehabilitation der Laryngektomierten beauftragte er den Schreibenden auch mit der Gründung der Phoniatrie und Logopädie in Basel.

\section{Dora-Seif-Preis und Präsidentschaften}

Für seine Verdienste auf dem Gebiet der Halstumoren wurde ihm 1977 der renommierte Dora-Seif-Preis verliehen. Werner Wey war zudem Präsident der Schweizerischen Gesellschaft für Oto-Rhino-Laryngologie, Hals- und Gesichtschirurgie und hat in diesem Amt Wesentliches für die Anerkennung unseres Fachgebietes als chirurgisches Fach im Gesamtgebäude der Medizin geleistet. So ist es seinem Engagement zu verdanken, dass die Stomatologie (Zahnheilkunde) in die medizinische Fakultät Basel integriert wurde. Als Präsident der Medizinischen Gesellschaft Basel verhandelte er ausserdem klug und umsichtig in der schwierigen Materie der gesamtschweizerischen Tarifverhandlungen.

Die Vorlesungen und Praktika von Werner Wey waren von den Medizinstudenten immer gut besucht, seine Eloquenz war ausserordentlich und er betreute geduldig unzählige Dissertationen. Als klinischer akademischer Lehrer hat er mehrere Generationen Hals-NasenOhrenärzte ausgebildet. Das feu sacrè für die ORL und das Arzttum brannte stets in seinem Herzen, auch nach seiner Emeritierung 1992. So blieb Werner Wey auch Ehrenmitglied der SGORL.

Vor zwei Jahren erlitt er eine Apoplexie. Ein schweres Schicksal für jemanden, der gern und schön gesprochen hat. Aber er gab nicht auf - er versuchte, so gut zu sprechen und zu schreiben, wie es eben ging. Und er besuchte weiterhin Vorträge, Konzerte und seine ehemaligen Schüler. Auch am letzten Dies academicus war er noch dabei.

Am 25. März ist Werner Wey im Alter von 91 Jahren verstorben. Familie, Freunde, ehemalige Schüler und $\mathrm{Pa}$ tienten haben Werner Wey in einem Gottesdienst am 6. April zu seiner letzten Ruhestätte in der Predigerkirche Basel begleitet. Wir werden ihn in stets ehrender, dankbarer und liebender Erinnerung behalten.

Prof. Dr. med. Dr. h. c. Joseph Sopko 